\title{
Assessment of Lens Culinaris Agglutinin-Reactive Fraction of Alpha Fetoprotein as an Early Diagnostic Marker for Hepatocellular Carcinoma among Sudanese Patients with Chronic Liver Disease
}

\author{
Yousif M. Shata ${ }^{1}$, Salma BM Mudawi ${ }^{2}$, Suliman S. Fedail ${ }^{3}$, Badr Aldeen Hassan Al Abd ${ }^{4}$, \\ Ammar Mohammed Ismaeil, ${ }^{5}$ Samia Mahdi Ahmed ${ }^{6, *}$ \\ ${ }^{1}$ International Medical Technologist, Sudan University of Science and Technology, Khartoum, Sudan \\ ${ }^{2}$ National Center for GI and Liver Disease, Ibn Sina hospital, Khartoum, Sudan \\ ${ }^{3}$ Consultant Physician (Gastroenterologist), Khartoum, Sudan \\ ${ }^{4}$ College of Medical Laboratory Sciences, University of Science \& Technology, Khartoum, Sudan \\ ${ }^{5}$ Faculty of Science and Technology, Neelain University, Khartoum, Sudan \\ ${ }^{6}$ Department of Clinical Chemistry, Faculty of Medical Laboratory Sciences Sudan University of Science and Technology, Khartoum, \\ Sudan \\ *Corresponding author: samiama@sustech.edu
}

Copyright $@ 2014$ Horizon Research Publishing All rights reserved.

\begin{abstract}
Hepatocellular carcinoma (HCC) is a common complication in patients with chronic viral hepatitis and liver cirrhosis. Detection of HCC at an early stage is critical for a favorable clinical outcome. This is a case-control, hospital-based study, aimed to determine the usefulness of Lens Culinaris Agglutinin-Reactive Fraction of Alpha Fetoprotein (AFP-L3) as an early diagnostic marker for HCC in Sudanese Patients with chronic liver diseases. Blood samples were collected from 25 patients with HCC, 32 patients with chronic liver diseases (cirrhosis and chronic $\mathrm{HBV} / \mathrm{HCV}$ ), and 30 healthy individuals as control. AFP-L3 and Total Alpha Fetoprotein (T.AFP) were measured by immunometric assay. AFP-L3 and T.AFP were elevated in all patients (chronic liver disease and HCC patients). Both markers were found to be elevated with the increase of tumor size, and with presence of focal liver lesion (being elevating with the increase of number of lesions).Both markers showed to be elevated until a year after onset of the disease, then, decreased by time. AFP-L3 and T.AFP were positively correlated with the increase of patient's age, but no significant difference was found between males and females in all types of patients. AFP-L3 is more specific for HCC, this encourage us to use AFP-L3 as adjunct marker for HCC diagnosis.
\end{abstract}

Keywords Hepatocellular Carcinoma, AFP-L3, Chronic Liver Disease

\section{Introduction}

Hepatocellular carcinoma is the fifth most common cancer in the world, with an incidence of $>20$ per 100,000 in China and eastern Asia and 8 to 10 per 100,000 in the United States. The most significant risk factors for $\mathrm{HCC}$ are chronic infection with hepatitis $\mathrm{B}$ or $\mathrm{C}$ virus ( $\mathrm{HBV}$ and $\mathrm{HCV}$, respectively) and hepatic cirrhosis. Individuals at risk for HCC are typically monitored with serial hepatobiliary ultrasounds, as well as other imaging techniques (e.g., CT scans), and serial measurements of alpha-fetoprotein (AFP).

AFP is a glycoprotein synthesized by the fetal yolk sac, fetal liver, testicular non-seminomatous germ cell cancers, and malignant hepatic cells. It is the most established marker of HCC. Reliance on AFP levels to detect HCC, however, is confounded by the fact that AFP may be elevated in individuals with chronic $\mathrm{HBV}$ or $\mathrm{HCV}$ infection and hepatic cirrhosis. The sensitivity and specificity of AFP for diagnosing $\mathrm{HCC}$ vary with the population studied and the cut-off value above which AFP is considered positive. They range from $52 \%$ to $80 \%$ and $90 \%$ to $98 \%$, respectively. 3

Measurement of an AFP glycoform may prove to be clinically superior to measuring AFP. Three glycoforms, determined by the degree of fucosylation of the $\mathrm{N}$-acetylglucosamine-linked sugar chain, have been identified. The glycoforms are separated in vitro by their ability to bind the lectin Lens culinaris agglutinin (LCA), a carbohydrate binding protein isolated from lentil seeds. AFP-L1 is non-LCA binding and the major glycoform found in individuals with nonmalignant hepatopathy (e.g., cirrhosis or chronic HBV infection). AFP-L2 has an intermediate LCA binding capacity and is primarily produced by yolk sac 
tumors. AFP-L3 is produced by malignant liver cells, binds to LCA with high affinity, and is the major glycoform found in individuals with $\mathrm{HCC}$ (Fig.1). ${ }^{4,5}$

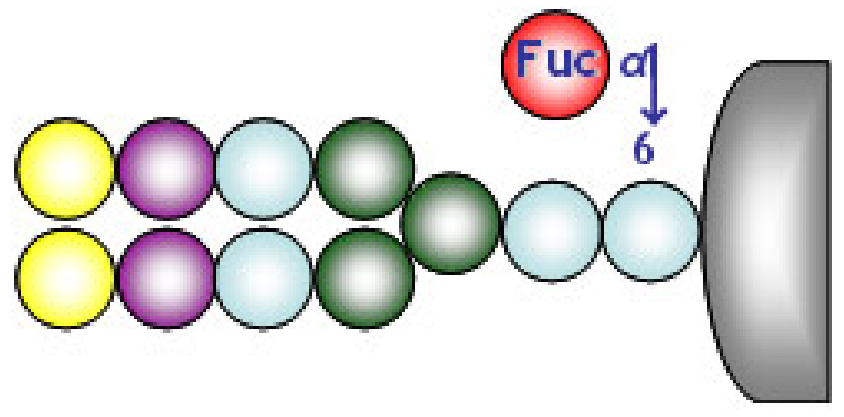

Figure 1. Sugar chain structure of AFP-L3

AFP-L3 levels (greater than 10\%) are associated with a 7 -fold increased risk of developing HCC within the next 21 months and can be elevated 3 to 21 months before HCC is detected by standard imaging techniques. ${ }^{6,7}$ The diagnostic sensitivity and specificity ranges from $36 \%$ to $66 \%$ and $77 \%$ to $95 \%$, respectively. ${ }^{8,9}$ Because AFP-L3 is produced by malignant hepatocytes, its measurement helps distinguish non-malignant hepatic disease from HCC. ${ }^{6,8-12}$ Malignant liver cells that produce AFP-L3 have an increased tendency for rapid growth, early invasion, and intra-hepatic metastasis, thus making AFP-L3 an indicator of poor prognosis in affected individuals. ${ }^{6,8-12}$

\section{Materials and Methods}

\subsection{Materials}

\subsubsection{Study area and Period}

This study was conducted on referred patients with HCC and chronic liver diseases at the hepatology unit (Ibn Sina hospital) from March 2011 to August 2012.

\subsubsection{Study Population}

The populations were divided into three groups:

(Non-malignant disease), both chronic hepatitis patients with $\mathrm{HBV} / \mathrm{HCV}$ infection and cirrhotic patients with no focal liver lesion.

Hepatocellular carcinoma patients (confirmed).

Control group: Healthy individuals with no history or evidence on clinical exam of liver disease with a normal liver on abdominal U/S, normal LFT, negative serological markers for $\mathrm{HBs} \mathrm{Ag}$ and $\mathrm{HCV}$ Abs and no history of alcoholic consumption.

\subsubsection{Study Design}

Case control hospital based study to assess the level of AFP-L3 in diagnosis of hepatocellular carcinoma (HCC) in the Sudanese population.

\subsubsection{Ethical Consideration}

Subjects enrolled in this study are in individuals with nonmalignant hepatopathy (e.g., cirrhosis and chronic $\mathrm{HBV} / \mathrm{HCV}$ infection), $\mathrm{HCC}$ and healthy individual. All those are involved after being fully informed by the aim of the study. In addition, an informed consent will be taken from every patient healthy control individual.

\subsubsection{Exclusion Criteria}

Patients with severe heart and brain disease, viral disease other than HBV and HCV infection, other parts of the body or organs associated with malignant tumor, pregnancy, children and those cases data collection is incomplete was excluded from this study. Healthy individual were completely excluded from Obesity, diabetes, jaundice, blood transfusion, alcoholic consumption, and chronic liver, renal, cardiac diseases.

\subsection{Methods}

\subsubsection{Blood Sampling}

Venous blood samples $(7.5 \mathrm{ml})$ from all patients and healthy control were collected in heparin $(2.5 \mathrm{ml})$ and plan $(5 \mathrm{ml})$ containers. The blood samples were centrifuged to get plasma and serum. Then Liver Function Test was done immediately after separation from plasma sample by using automated biochemical analyzer (HITACHI). By using ELISA (TECAN) screened HBV and HCV to control group and measured T.AFP, AFP-L3 to all population enrolled in this study via stored serum sample at $-20^{\circ} \mathrm{C}$.

\subsubsection{Measuring of Human alpha-fetoprotein Lens Culinaris Agglutinin 3(AFP-L3)}

The microplate provided in this kit has been pre-coated with an antibody specific to AFP-L3. Standards or samples are then added to the appropriate microtiter plate wells with a Horseradish Peroxidase (HRP)-conjugated antibody preparation specific for AFP-L3 and incubated. Then substrate solutions are added to each well. The enzyme-substrate reaction is terminated by the addition of a sulphuric acid solution and the color change is measured spectrophotometrically at a wavelength of $450 \mathrm{~nm} \pm 2 \mathrm{~nm}$. The concentration of AFP-L3 in the samples is then determined by comparing the O.D. of the samples to the standard curve.

Reference value: The concentration in normal human serum sample is $0-4 \mathrm{ng} / \mathrm{ml}$.

\subsubsection{Measuring of Total Alpha-fetoprotein (T.AFP)}

The DRG AFP ELISA Kit is a solid phase enzyme-linked immunosorbent assay (ELISA) based on the sandwich principle. The microtiter wells are coated with a monoclonal [mouse] antibody directed towards a unique antigenic site on an AFP molecule. An aliquot of patient sample containing endogenous AFP is incubated in the coated well with enzyme conjugate, which is an anti AFP antibody conjugated 
with horseradish peroxidase. After incubation, the unbound conjugate is washed off. The amount of bound peroxidase is proportional to the concentration of AFP in the sample. Having added the substrate solution, the intensity of color developed is proportional to the concentration of AFP in the patient sample.

\subsection{Calculation of Results}

Standard curve was used to determine the amount of an unknown sample, by reducing the data using computer professional software (Curve Exert 1.3) capable of generating a four-parameter logistic (4-PL) curve-fit. As an alternative, was constructed a standard curve by plotting the absorbance for each standard on the $\mathrm{x}$-axis against the concentration on the y-axis and drawing a best fit curve through the points on the graph. The data were linearized by plotting the log of the AFP-L3 and T.AFP concentrations versus the $\log$ of their O.D. (450nm) and the best-fit line was determined by regression analysis.

\subsection{Statistical Analysis}

Data was statistically analyzed using SPSS software program and presented as mean \& SD. The analysis of variance and the difference among the means were done for significance at 5\% level using Mann- Whitney test, the relationship between variables were determined using correlation analysis, and One Way ANOVA test for multiple comparison was used to asses association between AFP-L3 as dependent variable and diseases duration as factor.

\section{Results}

\subsection{Types of Liver Diseases Regarding AFP-L3 and T.AFP}

The means of AFP-L3 and T.AFP in chronic liver diseases (HBV, HCV\& liver cirrhosis) were found to be (1.1, 7.2, 2.5 $\mathrm{ng} / \mathrm{ml}) \&(7,13.1,19.7 \mathrm{IU} / \mathrm{ml})$ respectively. There were significant differences in the means of both markers among chronic liver diseases (HBV, HCV\& liver cirrhosis) compared to healthy control groups; AFP-L3 ( $\mathrm{P}<0.006$, $0.006,0.006) \&$ T.AFP $(\mathrm{P}<0.001,0.001,0.000)$ respectively. As well as highly significant difference in mean of AFP-L3 \& T.AFP among HCC patients $(82 \mathrm{ng} / \mathrm{ml} \& 110 \mathrm{IU} / \mathrm{ml})$ compared to healthy control groups $(0.8 \mathrm{ng} / \mathrm{ml} \& 1.4$ $\mathrm{IU} / \mathrm{ml}) .(\mathrm{P}<0.000, \quad 0.000$ respectively $)$ by applying Mann-Whitney test (Table1).

\subsection{AFP-L3 Serum Level and T.AFP according to disease Duration}

There were highly significant difference among patients who had disease duration of ( $<6$ months \& 6 months- 1 year) compared to healthy control groups, but no significant difference observed regarding the mean of AFP-L3 and T.AFP between patients who had disease duration of ( 1-2 years $\&>2$ years) compared to healthy control groups by applying One Way ANOVA (Table2).

Table 1. Type of liver diseases

\begin{tabular}{|c|c|c|c|c|}
\hline & Diseases & Mean & SD & P-value \\
\hline \multirow{4}{*}{$\begin{array}{c}\text { AFP-L3 } \\
(\mathrm{ng} / \mathrm{ml})\end{array}$} & HCC & 82 & 48.2 & 0.000 \\
\cline { 2 - 5 } & HBV & 1.1 & 0.3 & 0.006 \\
\cline { 2 - 5 } & HCV & 7.2 & 9.3 & 0.006 \\
\cline { 2 - 5 } & Cirrhosis & 2.5 & 2.6 & 0.006 \\
\hline \multirow{4}{*}{$\begin{array}{c}\text { T.AFP } \\
\text { (IU/ml) }\end{array}$} & Control & 0.8 & 0.3 & \\
\cline { 2 - 5 } & HCC & 110 & 79.9 & 0.000 \\
\cline { 2 - 5 } & HBV & 7 & 8 & 0.001 \\
\cline { 2 - 5 } & Cirrhosis & 19.1 & 14.7 & 0.001 \\
\cline { 2 - 5 } & Control & 1.4 & 1.13 & 0.000 \\
\hline
\end{tabular}

Table 2. Disease duration

\begin{tabular}{|c|c|c|c|c|}
\hline & Disease duration & Mean & SD & P-value \\
\hline \multirow{4}{*}{$\begin{array}{c}\text { AFP-L3 } \\
\text { (ng/ml) }\end{array}$} & $<6$ months & 53.6 & 54.6 & 0.000 \\
\cline { 2 - 5 } & 6 months- 1 year & 80.01 & 55.3 & 0.000 \\
\cline { 2 - 5 } & $1-2$ years & 13.2 & 26.2 & 0.303 \\
\cline { 2 - 5 } & $>2$ years & 7.6 & 25 & 0.539 \\
\hline \multirow{4}{*}{$\begin{array}{c}\text { T.AFP } \\
\text { (IU/ml) }\end{array}$} & Control & 0.8 & 0.3 & \\
\cline { 2 - 5 } & < 6 months- 1 year & 107.6 & 92.1 & 0.000 \\
\cline { 2 - 5 } & $>2$ years & 25.5 & 29 & 0.175 \\
\cline { 2 - 5 } & Control & 1.4 & 1.13 & 0.361 \\
\hline
\end{tabular}

Table 3. Focal liver lesions

\begin{tabular}{|c|c|c|c|c|}
\hline & $\begin{array}{c}\text { Focal liver } \\
\text { lesion }\end{array}$ & Mean & SD & P-value \\
\hline \multirow{2}{*}{$\begin{array}{c}\text { AFP-L3 } \\
(\mathrm{ng} / \mathrm{ml})\end{array}$} & Yes & 87.3 & 45.4 & \multirow{2}{*}{0.000} \\
\cline { 2 - 4 } & No & 8.6 & 24.4 & \\
\hline \multirow{2}{*}{$\begin{array}{c}\text { T.AFP } \\
(\mathrm{IU} / \mathrm{ml})\end{array}$} & Yes & 113.9 & 87.3 & \multirow{2}{*}{0.000} \\
\cline { 2 - 4 } & No & 21.6 & 38.6 & \\
\hline
\end{tabular}

\subsection{Comparison between Patients Who Had Focal Liver} Lesion and Patients without Lesion Regarding both Markers

The mean of AFP-L3 and T.AFP in patients with focal liver lesion were found to be $87.3 \mathrm{ng} / \mathrm{ml}$ and $113.9 \mathrm{IU} / \mathrm{ml}$ 
respectively. The mean of both markers were significantly higher in patients with focal liver lesion compared with patients who had no focal liver lesion $(\mathrm{P}<0.000,0.000$ respectively) by applying Mann-Whitney test (Table3).

\subsection{Time of HCC Detection}

The mean of both markers showed an elevate during the first year of detecting HCC then, gradually decreased by progress of time (Table4).

Table 4. Time of HCC detection

\begin{tabular}{|c|c|c|c|}
\hline & Time of HCC detection & Mean & SD \\
\hline \multirow{3}{*}{$\begin{array}{r}\text { AFP-L3 } \\
(\mathrm{ng} / \mathrm{ml})\end{array}$} & $<1$ year & 92.8 & 43.3 \\
\hline & $1-2$ years & 61.2 & 52.6 \\
\hline & $>2$ years & 49.7 & 68.3 \\
\hline \multirow{3}{*}{$\begin{array}{l}\text { T.AFP } \\
\text { (IU/ml) }\end{array}$} & $<1$ year & 123.2 & 78.9 \\
\hline & $1-2$ years & 100.4 & 92.3 \\
\hline & $>2$ years & 41.9 & 53.8 \\
\hline
\end{tabular}

\subsection{Relation of Tumor size with AFP-L3 and T.AFP}

The mean of AFP-L3 and T.AFP in different sizes of HCC were $(52.3,60.7,110.3 \mathrm{ng} / \mathrm{ml} \& 99.5,92.3,112.4 \mathrm{IU} / \mathrm{ml}$ respectively). High significant difference was found in the means of both markers considering the size of HCC (2-5 $\mathrm{cm},>5 \mathrm{~cm})$ when compared to healthy control groups (AFP-L3: $\mathrm{P}<0.000,0.000$ \& T.AFP: $\mathrm{P}<0.000,0.000$ respectively) by applying Mann-Whitney test (Table5).

Table 5. Sizes of Tumors

\begin{tabular}{|c|c|c|c|c|}
\hline & $\begin{array}{c}\text { Size Of } \\
\text { tumor }\end{array}$ & Mean & SD & P-value \\
\hline \multirow{4}{*}{$\begin{array}{c}\text { AFP-L3 } \\
(\mathrm{ng} / \mathrm{ml})\end{array}$} & $<2 \mathrm{~cm}$ & 52.3 & 133.4 & $*$ \\
\cline { 2 - 5 } & $2-5 \mathrm{~cm}$ & 60.7 & 84.3 & 0.000 \\
\cline { 2 - 5 } & $>5 \mathrm{~cm}$ & 110.3 & 77.3 & 0.000 \\
\hline \multirow{4}{*}{$\begin{array}{c}\text { T.AFP } \\
(\mathrm{IU} / \mathrm{ml})\end{array}$} & 2 Control & 0.8 & 0.3 & \\
\cline { 2 - 5 } & $<2 \mathrm{~cm}$ & 99.5 & 71.3 & $*$ \\
\cline { 2 - 5 } & $2-5 \mathrm{~cm}$ & 92.3 & 54.2 & 0.000 \\
\cline { 2 - 5 } & Control & 112.4 & 13.3 & 0.000 \\
\hline
\end{tabular}

* Very small number of patients to be compared.

\subsection{Number of Mass Lesions in HCC Patients}

The means of both markers in single and pair mass lesions on the liver of HCC patients were found to be (AFP-L3: 69.8, $96.8 \mathrm{ng} / \mathrm{ml} \&$ T.AFP: $108.3,142.7 \mathrm{IU} / \mathrm{ml}$ ). Highly significant difference was found in the means of AFP-L3 and T.AFP in HCC patients compared to healthy control groups $(\mathrm{P}<0.000$,
$0.000 \quad \& \quad 0.000, \quad 0.000$ respectively) by applying Mann-Whitney test (Table6).

Table 6. Number of mass lesions

\begin{tabular}{|c|c|c|c|c|}
\hline & No. of lesions & Mean & SD & P-value \\
\hline \multirow{3}{*}{$\begin{array}{c}\text { AFP-L3 } \\
(\mathrm{ng} / \mathrm{ml})\end{array}$} & 1 lesion & 69.8 & 53.6 & 0.000 \\
\cline { 2 - 5 } & 2 lesions & 96.8 & 43.2 & 0.000 \\
\hline & Control & 0.8 & 0.3 & \\
\hline \multirow{3}{*}{$\begin{array}{c}\text { T.AFP } \\
(\mathrm{IU} / \mathrm{ml})\end{array}$} & 1 lesion & 108.3 & 86.9 & 0.000 \\
\cline { 2 - 5 } & 2 lesions & 142.7 & 80.5 & 0.000 \\
\cline { 2 - 5 } & Control & 1.4 & 1.13 & \\
\hline
\end{tabular}

\subsection{Correlations between Age Factor and Serum Level of AFP-L3 and T.AFP}

AFP-L3 and T.AFP levels were positively correlated with increase of patients age $(\mathrm{P}<0.000,0.001)$ (Table7).

Table 7. Factor of age

\begin{tabular}{|c|c|c|}
\hline Factor & Tumor Markers & Sig (2-tailed) \\
\hline \multirow{2}{*}{ Age } & AFP-L3 $(\mathrm{ng} / \mathrm{ml})$ & 0.000 \\
\cline { 2 - 3 } & T.AFP $(\mathrm{IU} / \mathrm{ml})$ & 0.001 \\
\hline
\end{tabular}

\subsection{Comparison between Males and Females Patients Regarding AFP-L3 and T.AFP}

The means of AFP-L3 and T.AFP in males patients were found to be $33 \mathrm{ng} / \mathrm{ml}$ and $51 \mathrm{IU} / \mathrm{ml}$ respectively; while in females patients were found to be $44 \mathrm{ng} / \mathrm{ml}$ and $62 \mathrm{IU} / \mathrm{ml}$ for AFP-L3 and T.AFP respectively; therefore, no significantly difference were found between males patients compared to females patients. (Table8).

Table 8. Males and females patients

\begin{tabular}{|c|c|c|c|c|}
\hline & Gender & Mean & SD & P-value \\
\hline \multirow{2}{*}{$\begin{array}{c}\text { AFP-L3 } \\
(\mathrm{ng} / \mathrm{ml})\end{array}$} & Male & 33 & 48 & \multirow{2}{*}{0.261} \\
\cline { 2 - 4 } & Female & 44 & 54 & \\
\hline \multirow{2}{*}{$\begin{array}{c}\text { T.AFP } \\
(\mathrm{IU} / \mathrm{ml})\end{array}$} & Male & 51 & 68 & \multirow{2}{*}{0.465} \\
\cline { 2 - 4 } & Female & 62 & 77 & \\
\hline
\end{tabular}

\section{Discussion}

Alpha fetoprotein (AFP) has been recognized as a serum marker for hepatocellular carcinoma since 1970s, when most patients with HCC were diagnosed at an advanced stage with clinical symptoms. ${ }^{13}$ Previous studies indicated that AFP levels are elevated both in patients with $\mathrm{HCC}$ and in those with chronic liver diseases, and the AFP levels widely overlapped between the two groups. ${ }^{14}$ To date, AFP-L3, an 
isoform of AFP, has been proposed as a complement or substitute for AFP in diagnosis of HCC. AFP can be fractionated by affinity electrophoresis into three glycoforms: L1, L2 and L3 based on the reactivity with the lectin lens culinaris agglutinin (LCA). AFP-L3 bind strongly to LCA via an additional $\alpha 1-6$ fucose residue attached at the reducing terminus of N- acetyl glucosamine. ${ }^{13,15}$ To the best of our knowledge, this is the first study in our country to assess serum AFP and AFP-L3 levels in patients with HCC and chronic liver diseases (HBV, HCV \& liver cirrhosis). Here, we demonstrated the statistically significant elevated the serum levels of AFP and AFP-L3 comparing between HCC patients and non-HCC patients. These findings are consistent with the previous studies that reported the levels of AFP and AFP-L3 was significantly different between patients with HCC and those without HCC (chronic hepatitis patients). ${ }^{13}, 16$, 17,22

In addition, we also demonstrated that AFP-L3 levels were highly significantly elevated with the tumor size. This finding is consistent with previous study that reported AFP-L3 levels to be related to tumors with rapid growth, large size, and portal vein invasion and with metastasis. ${ }^{18,19}$ 22,25

This study revealed that, the levels of T.AFP and AFP-L3 were elevated at early progression of liver diseases and $\mathrm{HCC}$ detection and statistically significant different observed, but the both marker levels were decreased by progress of time and no significant different observed. This finding is quite consistent with previous study, which reported, that AFP and AFP-L3 levels decline to normal levels with effective therapy, rising levels suggest diseases progression or recurrence. ${ }^{18}$

Our study showed no significant different among male and female patients regarding T.AFP and AFP-L3. In addition, we found positive correlation between the levels of both marker and increase the age of patients.

Oka et al have demonstrated that the characteristic of having an advanced tumor, including the number of tumors, maximum diameter, tumor spread, portal vein invasion, tumor stage, and tumor classification, were associated with a positive AFP-L3 in HCC patients. ${ }^{20}$ The total AFP value has also been associated with many of the same prognostic features. In the present study, statistically highly significant different was observed in the levels of T.AFP and AFP-L3 among the number of tumor lesions in HCC patients and healthy control groups. In addition, we demonstrated that T.AFP and AFP-L3 levels were significantly elevated in the patients has focal liver lesion compared to those with no lesion .

Patients with positive AFP-L3 have worse liver function, large tumors, more advanced cancer, and lower survival than HCC patients with negative AFP-L3. The serum AFP concentration is also elevated in patients with chronic liver diseases and it has been demonstrated that AFP-L3 is useful marker for differentiation of elevated T.AFP level in hepatocellular carcinoma and chronic liver diseases. ${ }^{21,23,24}$

Studies for screening and diagnosing of Sudanese patients with combination of three biomarkers T.AFP, AFP-L3 and DCP are needed to provide more data and corroborate earlier findings. The good news is that a study was launched by the Dr.Fayza Ahmed in hepatology unit- Ibn Sina hospital on Jan 2013 to assess the clinical usefulness of T.AFP, AFP-L3 and DCP in Sudanese patients with HCC and chronic liver disease. Studies show that the biomarkers AFP-L3, AFP and DCP are complementary. That is, the expression of each biomarker is only partially overlapping in HCC patients ${ }^{26-28}$. Currently, AFP, AFP-L3, and DCP are widely and routinely used to screen for HCC in Japan, and these tests are covered by Japan's national health insurance as serological biomarkers to screen for HCC in clinical settings. Since most high-risk patients were closely followed before developing HCC, HCC nodules were detected in the early stage in more than $60 \%$ of patients in Japan ${ }^{29}$. Therefore, combined measurement of all three biomarkers is clinically useful.

\section{Conclusion}

T.AFP and AFP-L3 provides different information on the liver cancer. T.AFP may be an indicator of tumor mass in the liver cancer while AFP-L3 measure malignant potential of the liver cancer cells. Sensitivity of total AFP may be related to clinical stage, mainly to tumor differentiation, while sensitivity of AFP-L3 related to aggressiveness of liver cancer .

T.AFP showed the highest elevated levels in patients with HCC, whereas AFP-L3 is slightly elevated.

These findings encourage us to use AFP-L3 in combination with T.AFP; this may be a clinically useful adjunct marker for diagnosis of HCC .

AFP-L3 provides complementary information to T.AFP for early recognition of malignant liver tumor.

\section{Acknowledgements}

This research paper would not have been possible without the support of many people. I would like to express my gratitude to Prof Hamza Khamis (Ibn Sina Hospital), Dr. Ibrahim Mohammed (Zakat Chamber), Dr. Alamin Zayed (WAMY), Dr. Mohamed Alkhediery and Mohamed Aljeily and my uncle Yehya Khalil for their financial support and Tag Elsir for technical support. My deepest appreciation goes to Dr. Fayza Ahmed, gives me constructive comments and warm encouragement.

\section{REFERENCES}

[1] Bosch FX, Ribes J, Borras J. Epidemiology of primary liver cancer. Semin Liver Dis. 1999; 19:271-285.

[2] American Cancer Society: Cancer Facts and Figures 2006. 
Atlanta, Ga: American Cancer Society, 2006.

[3] Lopez JB, Thambyrajah V, Balasegaram, et al. Appropriate cut-off levels for serum alpha-fetoprotein in hepatocellular carcinoma. Diagnostic Oncology. 1994-1995; 4:287-291.

[4] Sato Y, Nakata K, Kato Y, et al. Early recognition of hepatocellular carcinoma based on altered profiles of alpha-fetoprotein. N Engl J Messd. 1993; 328:1802-1806.

[5] Li D, Mallory T, Satomura S. AFP-L3: a new generation of tumor marker for hepatocellular carcinoma. Clin Chim Acta. 2001; 313:15-19.

[6] LBA AFP-L3 Manufacturer's Package Insert, Rev. \#1/0505DDD00K, Wako Pure Chemical Industries, Ltd., $(1 / 05 / 05)$

[7] Kumada T, Nakano S, Takeda I, et al. Clinical utility of Lens culinaris agglutinin-reactive alpha-fetoprotein in small hepatocellular carcinoma: special reference to imaging diagnosis. J Hepatol. 1999; 30:125-130.

[8] Taketa K, Endo Y, Sekiya C, et al. A collaborative study for the evaluation of lectin-reactive $\alpha$-fetoprotein in early detection of hepatocellular carcinoma. Cancer Res. 1993; 53:5419-5423

[9] Oka H, Saito A, Ito K, et al. Multicenter prospective analysis of newly diagnosed hepatocellular carcinoma with respect to the percentage of Lens culinaris agglutinin-reactive $\alpha$-fetoprotein. J GastroenHepatol. 2001; 16:1378-1383 .

[10] Tada T, Kumada T, Toyoda H, et al. Relationship between Lens culinaris agglutinin-reactive $\alpha$-fetoprotein and pathological features of hepatocellular carcinoma. Liver Int. $2005 ; 25: 848-853$

[11] Yoshida S, Kurokohchi K, ArimaKeiji, et al. Clinical significance of Lens culinaris agglutinin-reactive fraction of serum $\alpha$-fetoprotein in patients with hepatocellular carcinoma. Int J Oncol. 2002; 20:305-309 .

[12] Toyoda H, Kumada T, Kiriyama S, et al. Prognostic significance of simultaneous measurement of three tumor markers in patients with hepatocellular carcinoma. ClinGastroenterolHepatol. 2006; 4:111-117 .

[13] Tateishi R, Yoshida H, Matsuyama Y, Mine N,Kondo Y, Omata M. Diagnostic accuracy of tumor markers for hepatocellular carcinoma: a systematic review. HepatolInt. 2008; $2: 17-30$

[14] Spangenberg HC, Thimme R, Blum HE. Serum markers of hepatocellular carcinoma. Semin Liver Dis. 2006; 26: 385-90.

[15] Marrero JA, Feng Z, Wang Y, et al. Alpha-fetoprotein, desgammacarboxyprothrombin, and lectin-bound alpha-fetoprotein in early hepatocellular carcinoma. Gastroenterology. 2009; 137: 110-8.

[16] Malaguarnera G, Giordano M, Paladina I, Berretta M, Cappellani A, Malaguarnera M. Serum markers of hepatocellular carcinoma. Dig Dis Sci. 2010; 55: 2744-55.

[17] Yamamoto K, Imamura H, Matsuyama Y, et al. AFP, AFP-L3, $\mathrm{DCP}$, and GP73 as markers for monitoring treatment response and recurrence and as surrogate markers of clinicopathological variables of HCC. J Gastroenterol. 2010; 45: $1272-82$.
[18] Li D, Mallory T, Satomura S. AFP-L3: a new generation of tumor marker for hepatocellular carcinoma. ClinChimActa. $2001 ; 313: 15-19$

[19] Yamashiki N, Seki T, Wakabayashi M, et al. Usefulness of Lens culinaris agglutinin A- reactive fraction of alpha-fetoprotein (AFP-L3) as a marker of distant metastasis from hepatocellular carcinoma. Oncol Rep. 1999; 6:1229-32

[20] Oka H, Saito A, Ito K, et al. Multicenter prospective analysis of newly diagnosed hepatocellular carcinoma with respect to the percentage of Lens culinaris agglutinin-reactive alpha-fetoprotein. J Gastroenterol Hepatol. 2001; 16:1378-83.

[21] Kumada T, Nakano S, Takeda I, et al. Clinical utility of Lens culinaris agglutinin-reactive alpha-fetoprotein in small hepatocellular carcinoma: special reference to imaging diagnosis. JHepatol. 1999; 30:125-30.

[22] Jong Young Choi, Seung Won Jung, Hee Yeon Kim, et al. Diagnostic value of AFP-L3 and PIVKA-11 in hepatocellular carcinoma according to total-AFP. World J Gastroentrol.2013; 19(3): 339-346.

[23] Mary Ann Comunale, Mengjun Wang, Nikhil Anbarasan, et al. Total serum glycan analysis is superior to lectin-ELISA for the early detection of hepatocellular carcinoma. Proteomics Clinical Application. 2013; 7:690-700.

[24] Yi X, Yu S, Bao Y. Alpha-fetoprotein-L3 in hepatocellular carcinoma: A meta-analysis. Clin Chim Acta. 2013; 425:212-20.

[25] Byam J, Renz J, Millis JM.Liver transplantation for hepatocellular carcinoma. Hepatobiliary Surg Nutr.2013; 2:22-30.

[26] Ertle JM, et al. A Combination of $\alpha$-Fetoprotein and Des- $\gamma$-Carboxy Prothrombin is superior in Detection of Hepatocellular Carcinoma. Digestion. 2013; 87:121-31.

[27] Choi Jy, et al. Diagnostic value of AFP-L3 and PIVKA-II in hepatocellular carcinoma according to total-AFP. World J Gastroenterol. 2013; 19:339-46.

[28] Hann HW, et al. Potential usefulness of highly sensitive AFP-L3\% and DCP in risk assessment in surveillance of patient at risk for hepatocellular carcinoma (HCC). DDW 2013 Poster tu 1048 [cited 25 Jun 2013]. http://www.wakodiagnostics.com/documents/ potential_usefulness_of_hsafp-13_and_dcp_ in_risk_assessment_in_surveillance hann_etal_tu1048_ddw_ 2013.pdf

[29] Song PP, Gao JJ, Inagaki Y, et al. Biomarkers: evaluation of screening for and early diagnosis of hepatocellular carcinoma in Japan and China. Liver Cancer 2013; 2:31-9. 